\title{
Clinical applications of breath testing
} Kelly M Paschke ${ }^{1}$, Alquam Mashir ${ }^{1}$ and Raed A Dweik ${ }^{1,2 *}$

\author{
Addresses: ${ }^{1}$ Department of Pathobiology/Lerner Research Institute, Cleveland Clinic, Cleveland, OH 44195, USA; ${ }^{2}$ Department of Pulmonary and \\ Critical Care Medicine/Respiratory Institute, Cleveland Clinic, Cleveland, OH 44195, USA \\ * Corresponding author: Raed A Dweik (dweikr@ccf.org) \\ FI000 Medicine Reports 2010, 2:56 (doi:10.3410/M2-56)
}

The electronic version of this article is the complete one and can be found at: http://fl000.com/reports/medicine/content/2/56

\begin{abstract}
Breath testing has the potential to benefit the medical field as a cost-effective, non-invasive diagnostic tool for diseases of the lung and beyond. With growing evidence of clinical worth, standardization of methods, and new sensor and detection technologies the stage is set for breath testing to gain considerable attention and wider application in upcoming years.
\end{abstract}

\section{Introduction and context}

With each breath exhaled thousands of molecules are expelled, providing a window into the physiological state of the body. The utilization of breath as a medical test has been reported for centuries as demonstrated by Hippocrates in his description of fetor oris and fetor hepaticus in his treatise on breath aroma and disease [1]. Even in modern times clinicians have noted distinct changes in the breath odor of patients with specific diseases such as diabetes, renal failure, and hepatic diseases [2-4]. However, it was Linus Pauling's milestone discovery of 250 unique substances present in exhaled breath that offered promising insight into breath testing [5]. Since this discovery, breath analysis has rapidly evolved as a new frontier in medical testing for disease states in the lung and beyond [1]. Breath analysis is now used clinically to monitor asthma, diagnose transplant organ rejection, diagnose Helicobacter pylori infection, detect blood alcohol concentration, and monitor breath gases during anesthesia, mechanical ventilation, and respiration, among numerous other applications $[1,6,7]$.

\section{Recent advances}

Breath analysis may offer a relatively inexpensive, rapid, and non-invasive method for detecting a variety of diseases. With recent advancements in mass spectrometry (MS) and gas chromatography MS (GC-MS), it is possible to identify thousands of unique substances, such as volatile organic compounds (VOCs) and elemental gases, in the breath [8]. Improved technologies such as selected-ion flow-tube MS (SIFT-MS), multi-capillary column ion mobility MS (MCC-IMS), and proton transfer reaction MS (PTR-MS) have provided real time, precise identification of trace gases in human breath in the parts per trillion range [9-11]. On the other hand, unlike traditional quantitative breath analysis, the electronic nose is essentially trained to recognize odor patterns using an array of gas sensors. The electronic nose has shown accuracy in the detection of lung cancer, pneumonia, and asthma with specificities and sensitivities ranging from 74$98 \%$, as well as in the discrimination between diseases such as chronic obstructive pulmonary disease and asthma [12-15]. Table 1 provides a selected list of the growing number of technologies being applied to breath testing.

More recent technological advancements in breath analysis have moved beyond measuring volatiles in the gas phase into measurement of semivolatiles and compounds dissolved in aerosolized droplets in exhaled breath condensate (EBC) and in exhaled breath vapor (EBV). Aerosolized droplets in EBC can be captured by a variety of methods and analyzed for a wide range of biomarkers, such as metabolic end products, proteins, cytokines, and chemokines, with expanding possibilities $[16,17]$. With 3000 volatile compounds identifiable using EBC and twice the volatile metabolite concentration compared to traditional breath gas analysis, this application has the potential to provide superior information about 
Table I. Current breath-based test technologies

\begin{tabular}{|c|c|c|}
\hline Spectrometry & Gas chromatography & Other \\
\hline Mid-infrared absorption spectroscopy & $\begin{array}{l}\text { Automated thermal desorption gas chromatography } \\
\text { mass spectrometry (ATD-GC-MS) }\end{array}$ & Chemiluminescense \\
\hline Multi pass cell-laser absorption spectroscopy & $\begin{array}{l}\text { Gas chromatography flame ionization } \\
\text { detection (GC-FID) }\end{array}$ & Electrochemical cell sensor technology \\
\hline Tunable diode laser absorption spectroscopy (TDLAS) & Gas chromatrography mass spectrometry (GC-MS) & Gas sensor array technology \\
\hline Cavity ring-down spectroscopy (CRDS) & Photoionization detection gas chromatography & Nanosensor technology \\
\hline Cavity leak-out spectroscopy (CALOS) & $\begin{array}{l}\text { Solid phase microextraction gas chromatography mass } \\
\text { spectrometry (SPME-GC-MS) }\end{array}$ & Infrared and para-magnetic sensors \\
\hline Cavity enhanced optical frequency comb spectroscopy & $\begin{array}{l}\text { Gas chromatography time of flight mass spectrometry } \\
\text { (GC-TOF-MS) }\end{array}$ & Calorimetry \\
\hline Integrated cavity output spectroscopy (ICOS) & $\begin{array}{l}\text { Gas chromatography differential mobility spectrometry } \\
\text { (GC-DMS) }\end{array}$ & Sol-gel sensor technology \\
\hline Laser magnetic resonance spectroscopy (LMRS) & $\begin{array}{l}\text { Gas chromatography ion mobility mass spectrometry } \\
\text { (GC-IMS-MS) }\end{array}$ & Laser based sensor technology \\
\hline Laser photoacoustic spectroscopy & $\begin{array}{l}\text { Gas chromatography/Fourier transform ion cyclotron } \\
\text { resonance mass spectrometry (GC/FT-ICR-MS) }\end{array}$ & \\
\hline Faraday-LMRS & Gas-liquid partition chromatography (GLPC) & \\
\hline Selected ion flow tube mass spectrometry (SIFT-MS) & $\begin{array}{l}\text { Gas chromatography electrolyzer-powered flame } \\
\text { ionization detector (GC-EFID) }\end{array}$ & \\
\hline \multicolumn{3}{|l|}{ Proton transfer reaction mass spectrometry (PTR-MS) } \\
\hline \multicolumn{3}{|l|}{ Faraday modulation spectroscopy } \\
\hline \multicolumn{3}{|l|}{ Ion trap (2D) and (3D) mass spectrometry } \\
\hline \multicolumn{3}{|l|}{ Time of flight mass spectrometry (TOF-MS) } \\
\hline \multicolumn{3}{|l|}{ Isotope ratio mass spectrometry (IR-MS) } \\
\hline \multicolumn{3}{|l|}{$\begin{array}{l}\text { Multi-capillary column ion mobility mass spectrometry } \\
\text { (MCC-IMS) }\end{array}$} \\
\hline \multicolumn{3}{|l|}{ High sensitivity (hs)-PTR-MS } \\
\hline \multicolumn{3}{|l|}{$\begin{array}{l}\text { Matrix assisted laser desorption/ionization time of } \\
\text { flight mass spectrometry (MALDI-TOF-MS) }\end{array}$} \\
\hline $\begin{array}{l}\text { Proton transfer reaction time of flight mass } \\
\text { spectrometry (PTR-TOF-MS) }\end{array}$ & & \\
\hline
\end{tabular}

breathprints of healthy and disease states $[8,18]$. EBV sampling has also yielded promising results as a new breath sampling method. EBV sampling pre-concentrates breath samples using a solid-phase microextraction fiber inserted into a modified RTube ${ }^{\mathrm{TM}}$, a common device also used in EBC sampling. This procedure provides the potential advantages of faster breath sampling and analysis, increased portability, minimal user training, use in contaminated environments, and no requirement for a power source. EBV sampling may yield additional compounds not detected in EBC and may provide greater sensitivity as a sampling method, expanding the spectrum of breath sampling [19].

\section{Implications for clinical practice}

The science of breath analysis is rapidly expanding, the technology is improving, and several new applications have been developed or are under commercial development. A major breakthrough over the past decade has been the increase in breath-based tests approved by the US Food and Drug Administration (FDA). Devices measuring common breath gases: oxygen, nitrogen, water vapor, and carbon dioxide in patient respiratory monitoring have served as a platform for technological growth in clinical breath testing applications. In particular, earlier devices, such as those providing the detection of blood alcohol concentration, H. pylori infection, lactose intolerance, and airway monitoring by end-tidal carbon dioxide, have demonstrated clinical benefits as well as diagnostic success in clinical breath testing. Table 2 provides a selected list of the breathbased tests currently approved by the FDA.

One recent landmark in clinical breath testing occurred in 2003 when the FDA approved the first device that measures the fraction of exhaled nitric oxide $\left(\mathrm{FE}_{\mathrm{NO}}\right)$ for asthma monitoring. The desktop $\mathrm{NIOX}^{\circledR}$ (currently NIOX $^{\circledR}$ FLEX) was followed by a handheld NIOX ${ }^{\circledR}$ MINO device (both by Aerocrine, Inc., Solna, Sweden) that received FDA clearance in 2008. Advantages provided by $\mathrm{FE}_{\mathrm{NO}}$ monitoring devices include its noninvasive nature, ease of repeat measurements, and use in adult and child populations with severe airflow obstruction where other techniques would be difficult or impossible to perform [20]. FDA approval of these devices has largely been attributed to the standardization 


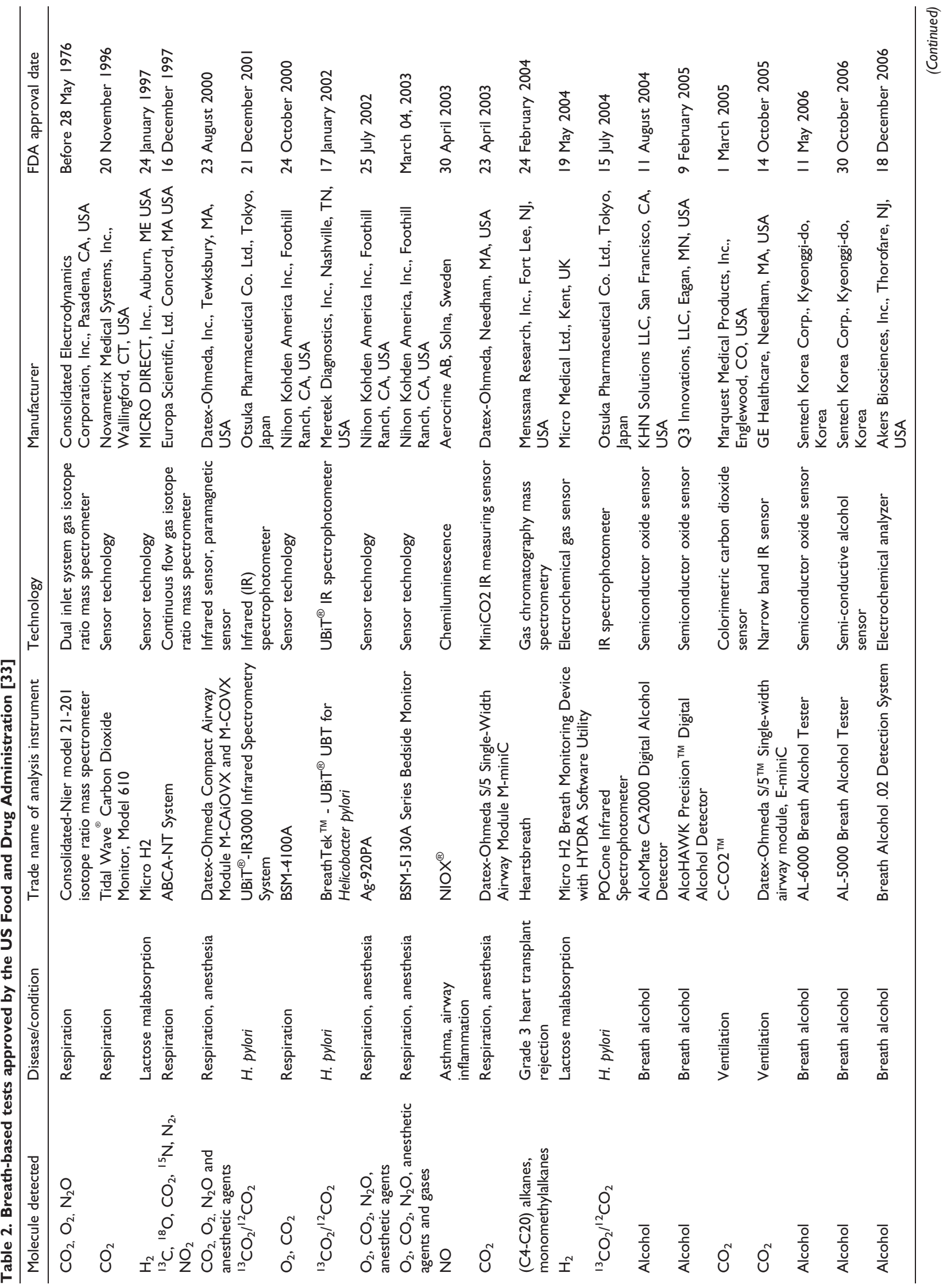




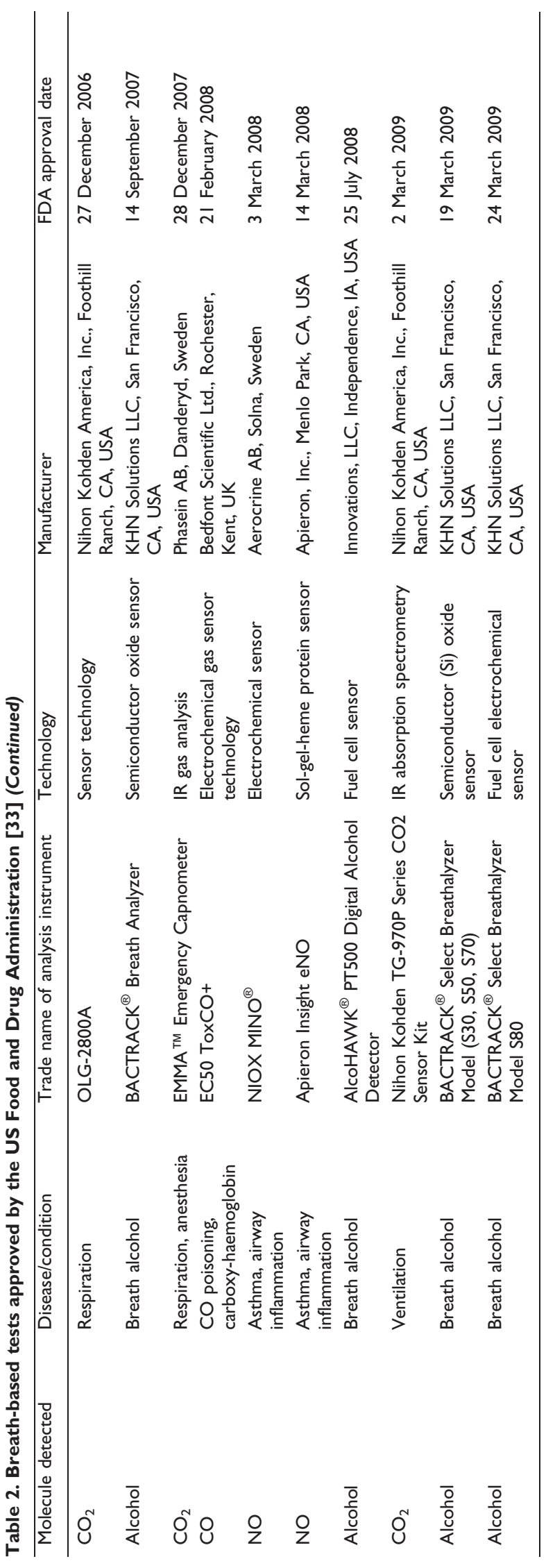

of clinical $\mathrm{FE}_{\mathrm{NO}}$ monitoring and detection via breath analysis [21]. In order for this simple yet powerful tool to achieve its potential, we need to further understand the roles that $\mathrm{FE}_{\mathrm{NO}}$ and similar biomarkers of disease play in different clinical settings and across populations, and their specific functions in disease.

A recent clinical application of breath testing has been in the diagnosis of lung cancer. Currently, clinicians rely on relatively expensive and invasive diagnostic tests, such as computed tomography exams, chest radiography, sputum analysis, and lung biopsies, which remain largely ineffective in early stage lung cancer diagnosis. Researchers have demonstrated success using trained dogs in the breath diagnosis of both early and late stage lung cancers with sensitivities and specificities approaching 99\%, providing promise for future lung cancer breath tests [22]. Breath testing may provide a promising alternative diagnostic tool for lung cancer as evidenced by numerous studies with specificities and sensitivities ranging from $71-94 \%$ [14,23-28]. However, in order to be useful as an upfront screening test for high-risk populations, as a tool to evaluate pulmonary nodules, or as a diagnostic test for lung cancer, a breath test should be at least 9095\% sensitive and specific [29].

As the field of breath research has developed over the past decade, the need for standardization in sampling has grown. Attempts at sampling only critical portions of exhaled breath have proven successful by using endtidal sampling, as evidenced by finding VOC concentrations most reflective of compounds dissolved in the blood [30]. End-tidal sampling (collecting breath only at the end of exhalation) has shown success over mixed expiratory sampling (collecting the entire exhaled breath) because samples are less likely to be diluted by mixing with dead space volume (inspired air not taking place in gas exchange) and ambient air. A useful application is buffered end-tidal on-line sampling, which measures VOC breath concentrations over a large mass range quickly and uses multiple MS technologies, such as SIFT-MS and PTR-MS, for breath analysis [31]. It is also promising because it uses on-line sampling (the sampling device is connected to the analytical device) versus less accurate off-line sampling (the sample is collected and later brought to the analytical device using reservoirs such as Tedlar ${ }^{\circledR}$ bags). Device calibration and validation have helped by accounting for exogenous VOCs and ambient air contamination in the sampling environment [19]. Since detection of many VOCs occurs at the parts per billion and parts per trillion levels, it is essential to control for exogenous sources of VOCs because ingestion of certain foods, medications, gut bacterial flora, and exposure to 
chemicals and pollution, amongst many other things, will alter VOCs in exhaled breath [32]. It is important for researchers to consider the change in the concentration of several VOCs in disease states as well as the utility of ranking systems for VOC predictability and new methods for accounting for ambient VOC sources, such as calculating alveolar gradients $[8,28]$. Despite receiving considerable attention in recent years, issues with standardization have been a major limitation of clinical breath testing. This has been evidenced by difficulties in establishing baseline VOC concentrations and the wide range of results represented in the literature for VOC concentrations in disease. Thus, it is necessary in the future to search for innovative methods for breath research.

There are numerous potential advantages for breath analysis as a clinical test. The method is non-invasive (the sample is relatively easy and painless to acquire), the sample is likely to be rich with information (a single test can scan for signatures of many abnormalities or markers of disease), it has the potential for low cost, and lends itself to easy administration. The field of breath testing has grown tremendously in recent years and with evolving technologies in sampling, sensor design, standardization, and analytical methods breath analysis has the potential to clinically benefit individuals on a global scale in the future.

\section{Abbreviations}

EBC, exhaled breath condensate; EBV, exhaled breath vapor; FDA, US Food and Drug Administration; $\mathrm{FE}_{\mathrm{NO}}$, fraction of exhaled nitric oxide; GC-MS, gas chromatography MS; MCC-IMS, multi-capillary column ion mobility MS; MS, mass spectrometry; PTR-MS, proton transfer reaction MS; SIFT-MS, selected-ion flow-tube MS; VOC, volatile organic compound.

\section{Competing interests}

The authors declare that they have no competing interests.

\section{Acknowledgements}

KMP, AM, and RAD are supported by a Third Frontier grant from the Ohio Department of Development. RAD is supported by a National Institutes of Health (NIH) grant (NIH-HL68863).

\section{References}

I. Dweik RA, Amann A: Exhaled breath analysis: the new frontier in medical testing. J Breath Res 2008:03030I.

2. Manolis A: The diagnostic potential of breath analysis. Clin Chem 1983, 29:5-15.
3. van den Velde S, Quirynen M, van Hee P, van Steenberghe D: Halitosis associated volatiles in breath of healthy subjects. J Chromatogr B Analyt Technol Biomed Life Sci 2007, 853:54-6I.

4. Di Francesco F, Fuoco R, Trivella M, Ceccarini A: Breath analysis: trends in techniques and clinical applications. Microchem J 2005, 79:405-10.

5. Pauling L, Robinson AB, Teranishi R, Cary P: Quantitative analysis of urine vapor and breath by gas-liquid partition chromatography. Proc Natl Acad Sci U S A 197I, 68:2374-6.

6. Mashir A, Dweik R: Exhaled breath analysis: the new interface between medicine and engineering. Adv Powder Technol 2008, 20:420-25.

7. Ward K, Yealy D: End-tidal carbon dioxide monitoring in emergency medicine, Part 2: Clinical applications. Acad Emerg Med 1998, 5:637-46.

8. Phillips M, Herrera J, Krishnan S, Zain M, Greenberg J, Cataneo RN: Variation in volatile organic compounds in the breath of normal humans. J Chromatogr B Biomed Sci Appl 1999, 729:75-88.

9. Ross BM: Sub-parts per billion detection of trace volatile chemicals in human breath using Selected lon Flow Tube Mass Spectrometry. BMC Res Notes 2008, I:4I.

10. Perl T, Carstens E, Hirn A, Quintel M, Vautz W, Nolte J, Junger M: Determination of serum propofol concentrations by breath analysis using ion mobility spectrometry. $\mathrm{Br}$ J Anaesth 2009, 103:822-7.

II. Wehinger A, Schmid A, Mechtcheriakov S, Ledochowski M, Grabmer C, Gastl GA, Amann A: Lung cancer detection by proton transfer reaction mass-spectrometric analysis of human breath gas. Int J Mass Spectrom 2007, 265:49-59.

12. Fens N, Zwinderman AH, van der Schee MP, de Nijs SB, Dijkers E, Roldaan AC, Cheung D, Bel EH, Sterk PJ: Exhaled breath profiling enables discrimination of chronic obstructive pulmonary disease and asthma. Am J Respir Crit Care Med 2009, 180:1076-82.

FI000 Factor 6.0 Must Read

Evaluated by Ronald Sorkness 06 Jan 2010

13. Taivans I, Jurka N, Balode L, Bukovskis M, Kopeika U, Ogorodnkis V, Kleperis J, Strazda G, Šilinš V, Martinsons A: Exhaled air analysis in patients with different lung diseases using artificial odour sensors. Proc Latvian Acad Sci 2009, 63:210-13.

14. Machado RF, Laskowski D, Deffenderfer O, Burch T, Zheng S, Mazzone PJ, Mekhail T, Jennings C, Stoller JK, Pyle J, Duncan J, Dweik RA, Erzurum SC: Detection of lung cancer by sensor array analyses of exhaled breath. Am J Respir Crit Care Med 2005, I7I:1286-9|.

15. Dragonieri S, Annema JT, Schot R, van der Schee MP, Spanevello A, Carratu P, Resta O, Rabe KF, Sterk PJ: An electronic nose in the discrimination of patients with non-small cell lung cancer and COPD. Lung Cancer 2009, 64:166-70.

16. Horvath I, Hunt J, Barnes PJ, Alving K, Antczak A, Baraldi E, Becher G, van Beurden W], Corradi M, Dekhuijzen R, Dweik RA, Dwyer T, Effros R, Erzurum S, Gaston B, Gessner C, Greening A, Ho LP, Hohlfeld J, Jobsis Q, Laskowski D, Loukides S, Marlin D, Montuschi P, Olin AC, Redington AE, Reinhold P, van Rensen EL, Rubinstein I, Silkoff $P$, et al.: Exhaled breath condensate: methodological recommendations and unresolved questions. Eur Respir J 2005, 26:523-48.

17. Grob NM, Aytekin M, Dweik RA: Biomarkers in exhaled breath condensate: a review of collection, processing and analysis. J Breath Res 2008:037004.

18. Cap P, Dryahina K, Pehal F, Spanel P: Selected ion flow tube mass spectrometry of exhaled breath condensate headspace. Rapid Commun Mass Spectrom 2008, 22:2844-50.

19. Martin AN, Farquar GR, Jones AD, Frank M: Human breath analysis: methods for sample collection and reduction of localized background effects. Anal Bioanal Chem 2010, 396:739-50.

20. Ozkan M, Dweik RA: Nitric oxide and airway reactivity. Clin Pulmonary Med 200I, 8:199-206. 
21. American Thoracic Society: Recommendations for standardized procedures for the on-line and off-line measurement of exhaled lower respiratory nitric oxide and nasal nitric oxide in adults and children-1999. This official statement of the American Thoracic Society was adopted by the ATS Board of Directors, July 1999. Am J Respir Crit Care Med 1999, 160:2104-17.

22. McCulloch M, Jezierski T, Broffman M, Hubbard A, Turner K, Janecki $T$ : Diagnostic accuracy of canine scent detection in early- and late-stage lung and breast cancers. Integr Cancer Ther 2006, 5:30-9.

23. Gordon SM, Szidon JP, Krotoszynski BK, Gibbons RD, O'Neill HJ: Volatile organic compounds in exhaled air from patients with lung cancer. Clin Chem 1985, 3 I:1278-82.

24. Phillips M, Gleeson K, Hughes JM, Greenberg J, Cataneo RN, Baker L, McVay WP: Volatile organic compounds in breath as markers of lung cancer: a cross-sectional study. Lancet 1999, 353:1930-3.

25. Di Natale C, Macagnano A, Martinelli E, Paolesse R, D'Arcangelo G, Roscioni C, Finazzi-Agro A, D’Amico A: Lung cancer identification by the analysis of breath by means of an array of nonselective gas sensors. Biosens Bioelectron 2003, 18:1209-18.

26. Phillips M, Cataneo RN, Cummin AR, Gagliardi AJ, Gleeson K, Greenberg J, Maxfield RA, Rom WN: Detection of lung cancer with volatile markers in the breath. Chest 2003, 123:2 II5-23.
27. Mazzone P, Hammel J, Dweik R, Na J, Czich C, Laskowski D, Makhail T: Diagnosis of lung cancer by the analysis of exhaled breath with a calorimetric sensor array. Thorax 2007, 62:565-68.

28. Phillips $M$, Altorki $N$, Austin $J \mathrm{H}$, Cameron RB, Cataneo $\mathrm{RN}$, Kloss R, Maxfield RA, Munawar MI, Pass HI, Rashid A, Rom WN, Schmitt $P$, Wai J: Detection of lung cancer using weighted digital analysis of breath biomarkers. Clin Chim Acta 2008, 393:76-84.

29. ATS/ERS recommendations for standardized procedures for the online and offline measurement of exhaled lower respiratory nitric oxide and nasal nitric oxide, 2005. Am J Respir Crit Care Med 2005, 171:912-30.

30. Di Francesco F, Loccioni C, Fioravanti M, Russo A, Pioggia G, Ferro M, Roehrer I, Tabucchi S, Onor M: Implementation of fowler's method for end-tidal air sampling. J Breath Res 2008, 2:037009.

3I. Herbig J, Titzmann T, Beauchamp J, Kohl I, Hansel A: Buffered endtidal (BET) sampling - a novel method for real-time breathgas analysis. J Breath Res 2008, 2:037008.

32. Szulejko JE, McCulloch M, Jackson J, McKee DL, Walker JC, Solouki T: Evidence for Cancer Biomarkers in Exhaled Breath. IEEE Sens J 2010, 10:185-210.

33. FDA Medical Devices. [http://www.fda.gov/MedicalDevices/default.htm] 